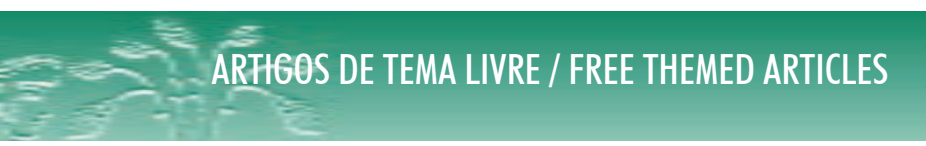

DOI: 10.12957/demetra.2016.22473

\title{
Un caso biográfico de insatisfacción corporal
}

\section{A biographic case of body dissatisfaction}

Natalia Solano-Pinto

Félix Díaz-Martínez'

${ }^{1}$ Universidad de Castilla-La

Mancha. Departamento de Psicología. Toledo, Espanhã.

Correspondência / Correspondence

Natalia Solano-Pinto

E-mail:natalia.solano@uclm.es

\section{Resumen}

En este artículo analizamos la historia de vida de una mujer, relatada en primera persona por ella misma y en tercera persona por su pareja, centrándonos en su preocupación por la imagen corporal y cómo afecta a diversos aspectos importantes en su vida cotidiana a lo largo del ciclo vital. El material de análisis son las respectivas entrevistas biográficas a una mujer de 33 años y a su pareja, un hombre de 40 , donde ambos relataron la vida de ella prestando especial atención a aspectos de imagen e insatisfacción corporal. El análisis se estructura en seis temas emergentes a lo largo de ambos relatos: "Mirada del otro y exposición del cuerpo", "embarazo", "modificar el cuerpo", "presión sociocultural”, "deseo masculino" y "el dilema del silencio". Prestamos especial atención al cambio de posicionamientos, sentimientos y hábitos en relación con el cuerpo a lo largo del ciclo vital, con momentos clave en la adolescencia y antes, durante y después de un embarazo. El análisis de biografías de personas no diagnosticadas nos permite entender diferentes formas de posicionarse en el contexto sociocultural de la cultura occidental en relación con el cuerpo. A su vez, puede facilitar el desarrollo de acciones para construir una mirada crítica hacia el contexto contribuyendo a que las mujeres elaboren su identidad y la vivencia de su cuerpo de una forma libre.

Palabras Clave: Imagen Corporal. Embarazo. Dieta Reductora. Biografía. 


\section{Abstract}

In this paper we analyze the life history of a woman, as told in first person by herself and in third person by her partner, focusing on her worries about body image and how they affect various important aspects of her everyday life through the life cycle. Our materials are the respective biographic interviews to a 33-year-old woman and her partner, a 40-year-old man, where they storied her life paying special attention to body image and dissatisfaction issues. The analysis is structured into six emerging themes along both stories: "The gaze of the other and body exposure", "Pregnancy", "Modifying the body", "Socio-cultural pressure", "Masculine desire", and "The silence dilemma". We pay special attention to changes in positioning, feelings and habits with respect to the body along the life cycle, with key moments in teenage, and before, during and after a pregnancy. The analysis of biographies of non-diagnosed persons may help us understand various ways of positioning in the socio-cultural context of Western culture with respect to the body. At the same time, it may facilitate the development of actions to construct a critical view on context, contributing to women's free elaboration of their identity and body experience.

Key words: Body Image. Pregnancy. Diet. Reducing. Biography.

\section{Introducción}

En este artículo hacemos una aproximación a la historia de vida de una mujer, relatada en primera persona por ella misma y en tercera persona por su pareja, para considerar una serie de procesos discursivos relacionados con su imagen corporal y otras preocupaciones asociadas.

Nos interesamos particularmente por el impacto que tuvo un proceso de embarazo en la vida de Juana (como llamaremos a la participante), pero recorreremos distintos momentos de su narración que hacen referencia a otros periodos del ciclo vital. Se trata de acceder a los recursos retóricos y narrativos que usa Juana a lo largo de su historia de vida (y los que usa su pareja en un relato paralelo) para analizar la articulación de discursos públicos en un caso particular.

El surgimiento de la categoría diagnóstica de trastorno alimentario corre paralelo con la consolidación de discursos que promueven la belleza femenina delgada y la cultura sofisticada. Así, Bishop ${ }^{1}$ ha deconstruido el discurso promovido por revistas de mujeres que las invita a alcanzar sus objetivos de belleza a través de una dieta saludable y cuidadosa y del ejercicio. Griffin \& Berry ${ }^{2}$ analizaron mensajes transmitidos en anuncios occidentales de comida para comprobar 
que el consumo de comida (particularmente la comida alta en grasas) se asocia culturalmente al libertinaje, el pecado y la debilidad.

Las preocupaciones académicas y profesionales por la imagen corporal surgen en el seno de estos desarrollos históricos y culturales.

Los sentimientos asociados al propio cuerpo, entre otros aspectos, son el resultado de la comparación entre la propia figura y el cuerpo ideal. ${ }^{3,4}$ Cuando de dicha comparación surge una gran diferencia y el propio cuerpo queda desvalorizado, la persona se siente mal. ${ }^{5}$ Como resultado de dicha insatisfacción la persona puede decidir controlar o modificar su cuerpo. Los medios de comunicación transmiten que todas las personas con el esfuerzo, la dieta y los productos adecuados, pueden tener el cuerpo con el peso y la silueta deseada, similar si así se desea a una top-model. ${ }^{6,7}$ En relación a este último aspecto, la silueta ideal es rectilínea de cintura hacia abajo, lo que supone pocas caderas y una tripa lisa. Sin embargo, esta propuesta es biológicamente inadecuada, más propia de una niña prepuberal o de un varón que de una mujer adulta. Este ideal corresponde a intereses económicos y convierte la insatisfacción corporal en una constante en las mujeres occidentales contemporáneas. Dicha insatisfacción lleva a muchas mujeres a realizar conductas para poder modificar el cuerpo, siendo prácticas socialmente aceptadas. ${ }^{8-10}$ Mernissi, ${ }^{11}$ doctora en Sociología, menciona que "una mujer es bella solo cuando aparenta tener 14 años..., al dar el máximo de importancia a esa imagen de niña y fijarla en la iconografía como ideal de belleza, condena a la invisibilidad a la mujer madura (p. 244). Esta misma autora resume así esta situación de la mujer occidental actual: "El harén (la prisión) de las mujeres occidentales es la talla 38" (p.237).

Dicha presión sociocultural es constante a lo largo de la vida de la mujer, aunque quizás existen momentos vitales especialmente vulnerables por los rápidos cambios corporales: La adolescencia y el embarazo son los más significativos ${ }^{12,13}$. En ambos casos se produce un proceso de construcción de identidad. En relación al embarazo, la mujer elabora su papel y su identidad como madre, pero igualmente se reconstruye la identidad en todas las áreas de la vida de la persona. Todo cambio, genera cierta inseguridad y en ese contexto la presión sociocultural tiene más impacto.

MacSween ${ }^{14}$ vincula el desarrollo del yo a lo largo del ciclo vital con las exigencias culturales contemporáneas sobre la mujer. Las mujeres y chicas tienen que encontrar equilibrio entre la feminidad pasiva y la independencia y el éxito masculino en las culturas patriarcales burguesas contemporáneas; la inanición representa una forma de atender a este conflicto, integrando un yo impenetrable e independiente (definido por la renuncia a comer) en un cuerpo fino y femenino.

Además, la vivencia del propio cuerpo suele mediar en las relaciones con otras personas..$^{15,16}$ En determinados momentos del ciclo vital de la mujer, la vivencia del propio cuerpo adquiere más relevancia. Así, en la adolescencia los cambios corporales y el proceso de su aceptación hacen que aumente la inseguridad relacionada con el cuerpo. ${ }^{17,18}$ En las niñas, uno de los cambios más notables en la pubertad es la primera menstruación, que en muchas culturas supone el paso tangible 
de la infancia a la adolescencia. Biológicamente supone la puesta en marcha del funcionamiento del sistema reproductivo que a su vez implicará un crecimiento acelerado durante los dos años siguientes. Se estima que las chicas suelen tener un aumento de peso de un $40 \%$ aproximadamente. ${ }^{19}$ Socialmente, el salto a la adolescencia se refleja en frases como "la niña se ha hecho mujer", acompañadas de cierta satisfacción al comprobar un desarrollo y crecimiento normalizado. Sin embargo, la joven tiene un doble desafío que se puede resumir en "duelo y aceptación", es decir, comenzar un proceso de duelo hacia los comportamientos aceptables en la niñez (como jugar) y hacia su cuerpo de niña, para afrontar un proceso de transición a la vida adulta. ${ }^{20}$

Los cambios evidentes en las mujeres se reflejan en el aumento de volumen de los pechos mientras que la silueta se perfila, creciendo las caderas y aumentando el tejido adiposo en la zona del abdomen, la tripa y los muslos. En la cultura occidental, los pechos de las mujeres son objeto de deseo y se entiende que, cuanto más voluminosos, más deseo sexual provocarán en el entorno masculino. Así, la adolescente tiene que lidiar en varios frentes: El cambio corporal; cómo afrontar la mirada del entorno; cómo vestir el cuerpo; y el propio proceso de identidad. ${ }^{4}$

En relación a la mirada del entorno, los cambios corporales pueden provocar comentarios jocosos o burlas. Toro ${ }^{21}$ constató que el 28\% de las chicas manifestaba haber sufrido críticas, por parte de su familia, en relación a su peso, cuerpo y forma de comer. Eisenberg ${ }^{22}$ obtuvo cifras similares: el 28.5\% informaban de críticas realizadas por la familia y el $14.6 \%$ mencionaban a compañeros y familia.

En relación al vestido, la ropa le da significado al cuerpo suponiendo un puente entre el yo y la imagen que se quiere mostrar, constituyendo un instrumento de comunicación social. ${ }^{23}$ En la actualidad, la moda se ha convertido en una forma de lenguaje social y global. ${ }^{24}$ En concreto, en la lencería femenina existe toda una tendencia a "apretar y subir", con una serie de sistemas más o menos sofisticados que realzan los pechos. La promoción del binomio poca cintura / pechos voluminosos propicia en muchas adolescentes el deseo de tener "pechos de moda", consumiendo lencería propia de mujer adulta o acudiendo al cirujano y, en definitiva, cosificando su cuerpo vistiéndolo con una gran carga sexual. ${ }^{25}$

Distintos estudios cualitativos han analizado cómo se articulan discursivamente las experiencias asociadas al cuerpo y la alimentación en el contexto de los $\mathrm{TCA}^{26-28} \mathrm{El}$ valor de la narración como recurso cultural para afrontar la problemática de los TCA se documenta en la proliferación de novelas biográficas sobre el tema. La autobiografía se ha constituido en un popular recurso para elaborar la experiencia personal, ayudar a otras sufrientes a confrontar el problema o para dignificar las complejidades de la condición de afectada ante el público. ${ }^{29,30}$ La novela de ficción realista promueve el reconocimiento de una realidad cultural y la reflexión sobre problemas experimentados por mucha gente en nuestros entornos cotidianos. ${ }^{31,32}$ 
La autobiografía nos ofrece la oportunidad de conocer una problemática muy teorizada desde los propios términos y estructuras de significado que usan sus protagonistas. El análisis del discurso narrativo se dirige en nuestro caso a comprender la complejidad de una experiencia común y preocupante con rigor, en sus contextos humanos y cerca de sus categorías vernáculas. Y la selección de una historia de vida de una mujer sin diagnóstico nos permite reconocer la extensión de la problemática más allá de personas que reciben atención clínica y al margen de las categorías de la evaluación y programación psicológica: en el seno del nicho cultural significativo en que se produce.

\section{Método}

Nuestro material para este análisis se compone de dos entrevistas biográficas, realizadas a Juana y a su pareja Paco.

Juana es una mujer de 33 años, administrativa y estudiante de Grado Universitario. Su índice de masa corporal en los últimos 6 años ha oscilado entre 21 y 23 correspondiendo a valores de normopeso. En el momento de la entrevista ha sido madre y tiene un bebé de 4 meses.

Paco es un hombre de 40 años, también administrativo. Su índice de masa corporal es de aproximadamente 23. Juana y Paco llevan 6 años viviendo juntos. También trabajan juntos.

La entrevista se ha realizado por separado y cada cual ha relatado la vida de Juana. La entrevistadora en ambos casos fue la primera autora. La entrevista a Juana se compone de 285 turnos (en torno a 7600 palabras) y la de Paco se compone de 107 turnos (en torno a 3800 palabras).

Este análisis forma parte de un estudio más amplio, que incluye 20 entrevistas biográficas a 5 personas diagnosticadas con TCA y sus correspondientes cuidadores principales, y a 5 personas sin diagnóstico, con características pareadas a las de las participantes en el grupo clínico, y familiares o parejas suyas (en analogía a los cuidadores principales de las participantes del grupo clínico). De manera que la muestra total se compone de una sub-muestra post-clínica y una sub-muestra control. Juana y su pareja Paco pertenecen a la sub-muestra no clínica, que fue seleccionada intencionalmente.

Ambos participantes dieron consentimiento informado por escrito para participar en el estudio, cumpliendo así con los criterios éticos de confidencialidad, anonimato y uso adecuado de la información personal en la investigación. La entrevista se estructuró como una historia de vida: La trayectoria vital y biográfica de Juana era el hilo temático principal. Intentamos estructurar la narración a lo largo de marcadores como lugares de residencia, instituciones educativas, parejas, relaciones familiares o lugares de trabajo. La pregunta que abría la entrevista invitaba a relatar "la historia de tu vida hasta hoy, las cosas más importantes que te sucedieron, las que te llevaron a ser como eres, tu proceso hasta hoy". 
Una vez iniciada la narración con esta pregunta genérica, la entrevista se desarrollaba a través de preguntas abiertas. La entrevistadora utilizó una guía flexible consistente en una lista de temas relacionados con la imagen corporal, invitando al participante a discutirlos oportunamente. Las entrevistas se registraron en audio y se transcribieron completas. El análisis se apoyó en el instrumento informático MaxQDA y cubre todas las referencias temáticas a las formas de Juana de experimentar su cuerpo.

\section{Resultados}

Hemos estructurado el análisis en seis temas emergentes a lo largo de ambos relatos: "Mirada del otro y exposición del cuerpo", "embarazo y cuerpo" "modificar el cuerpo", "presión sociocultural”, "el deseo masculino" y "el dilema del silencio".

\section{Mirada del otro y exposición del cuerpo}

En el siguiente fragmento Juana describe el momento de su menarquia y su sentir ante dicho hecho.

38 Juana: nochebuena. ja que yo fui al baño y de repente uy. me puse papel higiénico y calladita. y claro esa noche la pasamos donde mis abuelos y total. que dejé la habitación y la cama. y nada yo ahí. como jooo. dejas de ser niño y lo vivía muy mal. diciendo "bueno. a lo mejor se va", jajaja, no quise decir nada pero al final fue noticia de toda la familia. porque luego fuimos a ver a la familia de mi madre y de mi padre. pues todo el mundo. bueno que! Jajaja

40 Juana: jajaja. "que ya me he enterado". jajaja. entonces nada luego pasaron unos días y de pronto eso desapareció y yo claro no estaba muy informada de esas cosas. pero me alegré porque pensé que era como que. que ya estaba. sabes como que habia pasado. y era "jo que bien ya puedo ser niña otra vez! y jugar y tal" y luego. no. jaja. así que eso lo viví un poquito mal. sabes. los cambios corporales también. los llevaba un poquito mal. yo me acuerdo que me apretaba así. en verano con el bañador me hacía así. me apretaba jaja. pero bueno 41 Entrevistadora: te apretabas el pecho. jaja

[...]46 Juana: lo que pasa que todo era diferente. pero no. me acuerdo, creo que en la clase de ciencias naturales teníamos que medirnos. al inspirar y al expirar. nada una tontería. entonces una compañera dijo "pues sí qué". yo no había hecho por vergüenza. sabes. por no ponérmelo. entonces una compañera dijo "pues déjalo y yo apunto lo tuyo y lo mí". pero no "porque lo tuyo no es lo mismo que lo mío. tú tienes más pecho" jaja. se habia dado cuenta jaja. y yo no. no. jaja. así que nada. eso es lo maá $\left(3^{a}\right)$. pero bueno

a Dentro de los fragmentos de entrevista, los números entre paréntesis indican tiempo de pausa en segundos. 
En el fragmento anterior, Juana recuerda el día exacto en el que tuvo su primera regla y describe las sensaciones que experimentó. Primero el intento de esconderlo usando papel higiénico y ocultando la información a su familia; la asociación entre la aparición de la menstruación y dejar atrás la infancia, el pensamiento mágico que surge cuando termina esa menstruación relacionado con la solución de un supuesto problema, la ilusión de que todo pueda volver a ser como antes. Este rechazo al hecho biológico corresponde al momento de "duelo- aceptación" propio de la transición de la infancia a la adolescencia; pero quizás el duelo de Juana se complicó, debido a la falta de información, así como la falta de confianza para acceder y tener una persona de referencia en el seno familiar a la que acudir. Por otra parte, Juana no aceptó los cambios corporales; en sus propias palabras, "los cambios corporales los llevaba mal". Dicha dificultad en la aceptación de su cuerpo queda plasmada en el siguiente fragmento:

97 Entrevistadora: oye y el cuerpo en esa época. como estaba?

98 Juana: era gris. durante toda mi vida hasta hace un año el cuerpo era como. no me ha gustado. como por ejemplo esto no me lo hubiera podido poner. no sé era como todo muy así. no sé muy bien.

99 Entrevistadora: muy? por el gesto que haces

100 Juana: a ver. sí. pues. muиu. como que no se note. como que no marque nada. como. no sé como por la idea de que no se me note que soy mujer. o algo así. o sea se tiene que marcar lo que sea pero. nada de trasparencias. vamos las trasparencias no. que no se vea el sujetador

101 Entrevistadora: que no se te marquen las tetas

102 Juana: claro. así como ropa sin forma. nada. o sea que muy femenina como que no. yo con vaqueros y muy así. entonces que ha cambiado ahora. pues el tema de mi hijo. con el embarazo jaja. vamos. jaja. bueno porque si. a lo mejor en la adolescencia que tenía que ir a comprar algo. un sujetador. yo no soy como por ejemplo que a mi madre estuviera ahi delante. o cambiarme delante de mi madre o de una prima o tal. no. yo es que me cerraba la puerta y me cambiaba. y si no había más remedio o tal. bueno pues así me lo quitaba y me lo poní con el pijama. jaja. con la camiseta puesta jaja para que no se me viera nada. jaja. o a lo mejor eso que me iba a comprar un sujetador y mi madre iba a ver! y yo "no mama". "no". jaja. "que haces!"

(...)105 Juana: así que claro. eso de ponerme el biquini. bañador o tal. bueno en la playa porque nadie me va a mirar y no conozco a nadie. pero en la piscina como un poco. (3) así que.

106 Entrevistadora: oye. a lo mejor es interpretación mía pero eso de ocultar las tetas?

107 Juana: más que ocultar es tapar. jaja. pero es eso que no se- (3) como que están ahí pero no hay que realzarlas o enseñarlas. ir con escote o no sé qué. ni el sujetador. ni nada. sabes es como una parte más. pero no como otras que a lo mejor se ponían algo así como estrechito para marcar o enseñando el sujetador. pues eso con trasparencias, eso. 
Juana describe su cuerpo como "gris", un cuerpo que no le gustaba, con un evidente rechazo a mostrarlo ante los demás. Habla de una forma de vestir caracterizada por la selección de ropa sin forma, que no marcarse, "que no se note que soy mujer". La invisibilidad ante la mirada del otro surge como solución ante las nuevas formas y atributos corporales. Los pechos, representación de atributos femeninos más visibles, no hay que "realzarlos o enseñarlos", como pueden hacer otras mujeres con ropas estrechas o trasparencias que dejan ver el sujetador. Ella decide no marcar ni enseñar ni tan siguiera en el ámbito más íntimo, ante la madre en particular, ante la familia en general.

En la adolescencia también se producen las primeras experiencias eróticas y/o sexuales. En el siguiente fragmento Juana describe ese momento:

112 Entrevistadora: muy bien, y en esos tonteos que hacias con las tetas?

113 Juana: jaja pues.

114 Entrevistadora: quiero decir con el cuerpo

115 Juana: jaja en general. protegerle. es míooo. jajaja. porque tampoco tuve una relación así seria sabes?. eran pues tonteo. pues a lo mejor pues seis meses. pero no eran los fines de semana cuando nos veíamos porque éramos del grupo de amigos que quedábamos los fines de semana y ya está. y se suponía que estabas saliendo. te llamabas por teléfono dos días a la semana y ya está. sabes?. y solo hubo uno que me tocó un poquito las tetas. que le dejé porque me gustaba. pero ya.

La entrevistada recuerda experiencias con parejas esporádicas que ella denomina "tonteos" que no llegan a nada; intercambio de teléfonos, conversaciones y poco más. Menciona también Juana como dejó que un chico le tocase los pechos sin llegar a más, impidiendo que le tocase los genitales y protegiendo su cuerpo, quizás esperando a un entorno de intimidad o confianza.

\section{Embarazo y cuerpo}

Cuando Juana queda embarazada, su relación con su cuerpo cambia de forma radical:

138 Entrevistadora: jaja. has mencionado antes que tu maternidad es estupenda y maravillosa

139 Juana: ah sí.

140 Entrevistadora: hasta hace un año mi cuerpo era y ahora

141 Juana: ja ja. si con la maternidad. yo creo que la sensibilización ja ja 
142 Entrevistadora: sí ja ja. te expones. pasa a ser algo público

143 Juana: ja ja. si completamente. madre mía la cantidad de cosas que hay por ahi. Ja ja. entonces realmente piensas que es un cuerpo?. no hay más ja ja

144 Entrevistadora: y eso te ha venido bien? cómo? porque no es solo exponerlo No? y efectivamente te das cuenta que es un cuerpo. sino que es un cambio de forma. de tamaño. te amplitud. vamos que es un mundo. vamos cuenta tú!

145 Juana: jaja. bueno si todo cambia. el cuerpo cambia y ahora se deforma porque. bueno sí. dices "pero si es cuerpo" jaja. las tetas antes parecía que era un símbolo de-.

(...)149 Juana: a ver cómo te lo digo. vamos que no se enfoca en el tema maternidad. se enfoca más en el tema femenino. hombre y mujer. vamos sexual. Ja ja. guarri. Ja ja. entonces ahora dices "no. no es así. ahora a comer!!!”, sí mola ja ja. y nada y eso. luego también. bueno pues eso que pierdes más. yo me acuerdo antes cuando iba al médico o al ginecólogo que era como. cerraba los ojos y pensaba "madre mía qué vergüenza". hacía como. la técnica del avestruz. no lo miro. jaja. y luego ya como que bueno. Ja ja. pero bueno las relaciones desde entonces cambian son mejores. yo le digo a Paco ja ja "creo que se me ha dado de sí" ja ja "me ha dado de si” jajaja

En etapas anteriores, el encubrimiento dejaba el cuerpo sin significado, en palabras de la entrevistada un cuerpo "gris" (línea 98). Sin embargo, en el embarazo adquiere una función de generar y dar vida y fundamentalmente de alimentar. Gracias a esta percepción de la función del cuerpo, se realiza un cambio de actitud en cuanto a la exposición del cuerpo. Puede sentirse segura y permanecer más cómoda cuando su cuerpo aparece públicamente con cierto protagonismo: En el médico, en el amamantamiento. Además, en esta funcionalidad se destaca el aumento de la satisfacción en las relaciones sexuales, como consecuencia del cambio puramente físico en los genitales femeninos. En palabras de Juana, "creo que se me ha dado de sí”.

\section{Modificar el cuerpo}

Los momentos vitales donde se producen cambios corporales requieren la puesta en marcha de procesos de identificación corporal. En el caso de Juana hay 5 momentos en esta línea: La adolescencia; el cambio de domicilio e independencia respecto a la familia de origen para pasar a iniciar la convivencia con su pareja; antes del embarazo; el embarazo propiamente dicho; y después de la gestación. En estos momentos, junto con los cambios corporales, Juana debe reconstruir su identidad. 
1. La adolescencia donde Juana decide tapar el cuerpo pasando este a ser "un cuerpo gris" (líneas 97-07).

2. Independencia familiar. En este caso, tal y como se refleja en el siguiente fragmento, se produce un incremento de peso de 6 kilos debido a un cambio de alimentación que consistía en probar platos o alimentos novedosos que parecían estar asociados a un momento de satisfacción vital. Juana opta por acudir a un centro de adelgazamiento rápido de dudosa profesionalidad.

282 Juana: no. nada del cuerpo nada. He hecho dos veces régimen en mi vida que fue cuando me vine aquí a vivir porque yo creo que empecé a engordar. bueno me puse a dieta un año después de venirme aquí a vivir 283 Entrevistadora: que pasaste de vivir con tus padres a vivir con (discurso interrumpido)

284 Juana: sí entonces cambias. "mira qué rico! vamos a comprar esto!” tal! ja ja o compras más de golosinas. entonces pues no sé cambias un poquito los hábitos y engordé como seis kilos. nada me puse con lo de "centro adelgazamiento" y nada eso lo perdí y luego ya la dieta esa que te comento de (3) y ahora próximamente ja ja

3. Antes del embarazo. Unos años después de iniciar la convivencia con su pareja, planifican tener hijos. Antes del embarazo, Juana deseaba perder peso:

179 Juana: Y nada fui y muy bien. porque me quitó cosas como leche azúcar y el trigo que son algunos de los alimentos que no me sientan bien y además es que lo noté que. me quité esas cosas y me sentía como con más energía me sentía mucho mejor.

perdí peso y además es que comía. porque había veces que como no podía leche y en ese momento comía muchas cosas de soja y a lo mejor desayunaba mucho. comía un cocido. Ja ja. vamos que comía una barbaridad. Jaj a. vamos que comía mucho. comía cosas más naturales y mejores que antes y me sentaban mejor y nada. entonces pues eso perdí peso y me quede así. hasta que me quedé embarazada. no vaya a ser que y entonces voy a aprovechar. jaja y aproveché bien

Como se aprecia en el fragmento, Juana decide en esta ocasión acudir a un profesional que diagnostica alergias alimentarias y elimina de la alimentación productos esenciales como la leche y los derivados del trigo, realizando, en palabras de Juana, "una dieta de limpieza". Sin entrar a debatir lo peligroso de estas recomendaciones en futuras gestantes, esta decisión lleva a Juana a perder peso aun comiendo mucha cantidad y tipos de alimentos en momentos del día inusuales (cocido en el desayuno). Para la entrevistada esto es un valor en alza: poder comer mucho y perder peso.

En la entrevista a la pareja también se enfatiza este supuesto valor, según comentaremos al hablar de "presión sociocultural". 
4. Embarazo. En el siguiente fragmento aparece descrito el cambio corporal que se produce durante la gestación.

157 Entrevistadora: y ahora cómo te llevas con tu cuerpo? porque dices que está dado de sí. yo te veo igual. pero bueno

(...)160 Juana: no Me he quedado con siete u ocho kilos más. bueno estoy un poquito así. sobre todo ahora que viene el verano pues no sé si me valdrá algún biquini o bañador. Ja ja. y lo del tema de la ropa. es que siempre parece que voy con uniforme ja ja. porque no tengo casi ropa que me valga. porque cuando me quedé embarazada había estado a dieta. a dieta previa. no era por perder peso sino que era dieta de limpieza. me decían los alimentos que no toleraba bien

$161(4)$

162 Entrevistadora: cogiste mucho peso en el embarazo?

163 Juana: si cogí mucho peso sí cogí 16 kilos . hasta los cuatro meses bien. pero a partir de ahi del quinto mes cogía un kilo por semana

164 Entrevistadora: tenias hambre. hambre ja ja

165 Juana: ja ja. era como "no puedo parar" jaja. y todo. todo. chocolate. Ja ja. y luego me dijeron. bueno ahora con la lactancia todavía no me puedo poner a régimen pero ahora ya he terminado la lactancia y voy a ver cuando empiezo

La pérdida de peso anterior al embarazo posiblemente favorece el aumento de 16 kilos durante el embarazo. Habitualmente para mujeres con normopeso previo a la gestación se recomienda un incremento de peso de 11.5 a 13 kilos. ${ }^{33}$ Sin embargo, culturalmente es común que se transmita la errónea creencia de poder comer siguiendo unos supuestos antojos y así, como dice Juana, "entonces voy a aprovechar y aproveché bien” (línea 179). Esta creencia podría estar reforzada porque durante el embarazo está justificado, socialmente, "ser gordita".

5. Después del embarazo: En este fragmento, la entrevistada refleja cómo se siente respecto a su cuerpo después del embarazo.

271 Entrevistadora: y alguna vez así como por el rechazo del cuerpo. qué sé yo. has dejado de comer. o has pensado que tenías que modificarlo

272 Juana: bueno Sé que tengo algunas conductas de controlarme un poco. como voy a ponerme a estudiar y jo me apetece un chupachús ja ja. eso. pero no de dejar de comer. además voy a decir imañana no voy a comer! . pues sabes como que no ja ja 
273 Entrevistadora: si acaso piensas algo pero no lo haces

274 Juana: no da. piensas algo pero jolín tengo que ponerme ya en serio porque que no que no y dejar de comer tampoco

Juana comenta en otro fragmento de la entrevista que decidió esperar el tiempo de lactancia para perder el peso ganado en el embarazo, para hacer cierto control en la alimentación consistente en suprimir picoteos (línea 165). Ya antes había manifestado su descontento hacia las formas corporales en el embarazo ("el cuerpo cambia y ahora se deforma”, línea 145), lo cual implica un rechazo hacia su peso actual y desagrado al no poder utilizar su ropa previa al embarazo. También antes (línea 160) mostró preocupación por futuras situaciones de exposición del cuerpo en la piscina y/o la playa. En definitiva, a Juana, su cuerpo actual en forma y peso le ocasiona sufrimiento y deseos de modificarlo. Por último, queda explícito que no existe intención de realizar otras manipulaciones alimentarias pero se hace tangible la incoherencia o la ambivalencia en la decisión de perder peso y el procedimiento a seguir por parte de Juana. También su pareja es consciente de este sufrimiento, (entrevista a Paco, línea 56): "está la pobre lamentándose", "la ropa no le sienta bien".

\section{Presión sociocultural}

La entrevista a Paco, marido de Juana, nos da la oportunidad de sumergirnos en algunos planteamientos sobre el cuerpo femenino, el deseo masculino heterosexual y las relaciones de cuidados en la pareja desde la subjetividad de Paco. En los siguientes fragmentos, Paco hace una serie de valoraciones generales sobre temas sociales y culturales en relación con el problema de Juana y desde la posición de pareja suya.

En el siguiente fragmento Paco hace referencia a las fases por las que pasó Juana en relación con su cuerpo:

56 Paco: [...] (3) empezó a ir a (3) un centro y bueno dejó de tomar unos alimentos que la venían mal o algo así. perdió peso también pero mucho peso Comía muchísimo. desayunaba incluso lentejas o cosas así o cocido para desayunar pero perdía peso. Se quedó delgada quizás excesivamente delgada hace ya tres o cuatro años aproximadamente. es un peso que quizás digan que es el peso que se lleva ahora que es pues eso muy poca carne. muy poca cintura. poca cadera. poco de todo pero ella no es así. (3) no tiene esa (3) esa. forma o esa estructura ósea que la permita estar tan delgada y luego cogió algo de peso antes del embarazo y durante el embarazo cogió bastante y está la pobre lamentándose de que la sobran todavía seis o siete kilos. pero bueno 
yo creo que lo vive ella mucho peor de lo que lo aprecian los demás porque después de un embarazo vamos hay cuatro top modelos a nivel mundial que a los tres meses están desfilando pero quizás la genética les haya dado ese cuerpo y tienen también sus preparadores físicos. sus nutricionistas. pero una persona normal que se dedica a cuidar de su hijo y a estudiar en sus ratos libres. estudia de once de la noche a dos de la mañana es muy dificil ponerse a tono y la pobre lo pasa mal porque la ropa no la sienta bien. no quiere comprarse ropa de la talla que usa ahora porque siempre tiene la esperanza de que va a perder peso. pero bueno como mi hermana lleva así como veinte años y yo conozco la historia pero es muy difícil y de hecho si baja peso será de forma paulatina no de un mes para otro. pero lo vive ella mucho peor que (3) que el resto.

Paco relata (a) una dieta que hizo Juana antes del embarazo, (b) sus fluctuaciones de peso durante el embarazo y después, y (c) sus malestares con su cuerpo en la actualidad.

Paco no cuestiona la necesidad de la dieta o los métodos del centro. Sin embargo, enfatiza la pérdida de peso desmesurada que lleva a su pareja a tener una figura más cercana a una silueta rectilínea pero que no corresponde a la "forma o estructura ósea" de Juana. Paco contrasta así el cuerpo ideal ("el que se lleva ahora”) con el de Juana, enfatizando la imposibilidad de esta de tener esa silueta.

Su siguiente comentario contrapone la fisonomía de "cuatro top modelos", bendecidas por la genética y por apoyos profesionales, a la de "una persona normal que se dedica a cuidar de su hijo y a estudiar en sus ratos libres" (Juana).

En pocos segundos, Paco se ha apoyado en dos posibles formas de entender la "normalidad": Por una parte, hay una tendencia a acentuar la delgadez que no se adapta bien al particular cuerpo de Juana; por otra parte, los casos particulares de modelos profesionales que perfilan cierto tipo ideal de cuerpo resultan incompatibles con las vidas reales de las personas normales.

Estos dos contrastes se coaligan en un argumento que denuncia la imposibilidad práctica de satisfacer un ideal de delgadez. El fragmento viene a dibujar la imagen de ideales del cuerpo compartidos como fondo de las preocupaciones y prácticas de control de Juana, insinuando que provienen de presiones socioculturales.

\section{El deseo masculino}

Más adelante, y al margen de la trayectoria biográfica de Juana, Paco tiene la oportunidad de hablar del cuerpo de las mujeres como objeto de deseo:

100 Entrevistadora: luego también. aprovecho y te pregunto también como hombre con casi casi con cuarenta . ¿qué te gusta a ti del cuerpo de una mujer? ¿qué destacas en general? 
101 Paco: yo creo que todo, la armonía del conjunto yo pienso que sin ser nada sospechoso de tener ningún tipo de patología que hay pocas cosas más bonitas en la relación que el cuerpo de una mujer. (3) todo. (3) el conjunto. las curvas. será que como hombre se te disparan las hormonas cuando ves a una mujer vamos. es una cosa. pero separándolo de cualquier tipo de (3) de (3) de acto pornográfico la mujer. yo qué sé una mujer en una playa en top less o tal si el cuerpo está más o menos proporcionado. para mí es suficiente. es un acto de belleza total

\section{Entrevistadora: y destacas la armonía}

103 Paco: sí, ahora se lleva mucho pecho y poca cadera. lo cual es bastante. yo lo que odio profundamente es y me da bastante repelús es la silicona en el pecho. me parece una aberración. totalmente anti atractiva también. saber que una persona . incluso en los hombres que se ponen silicona o prótesis en los glúteos. o sea me parece (3) el fruto de la sociedad actual

La pregunta (100) presupone que Paco aprecia el cuerpo de las mujeres, genéricamente, "como hombre con casi cuarenta”. Pide la descripción de un ideal. Paco responde coherentemente y aporta un homenaje a la mujer como objeto de admiración desde la perspectiva del hombre como sujeto de contemplación. Su descripción apela al mito biologicista del varón que por su misma constitución reacciona con deseo ante la mujer.

La descripción en la línea 101 se apoya en un contraste entre lo natural-originario y lo socialartificial. Se desmarca "de cualquier tipo de acto pornográfico" (siendo la pornografía una industria de producción activa de particulares imágenes de cuerpos); ubica el deseo en lugares comunes ("en una playa en top less o tal”); se apoya en valores absolutos, afirmaciones de normalidad y formulaciones extremas, ${ }^{34,35}$ "sin ser nada sospechoso de tener ningún tipo de patología”, "todo, el conjunto", "belleza total".

En la línea 103, Paco contrasta esos impulsos naturales con la introducción artificial de silicona o prótesis, que es "social". Frente a la apreciación de "las curvas", o la proporcionalidad, Paco rechaza un modelo de "mucho pecho y poca cadera" que "ahora se lleva". Las curvas y las formas proporcionadas se han presentado como propiedades naturalmente hermosas; la introducción de silicona en el pecho de la mujer se presenta como antinatural, "el fruto de la sociedad actual".

Sin embargo, el homenaje de Paco a la mujer hermosa atiende a sus curvas más que a las estrechas líneas del paradigma de delgadez. Y, aunque Paco habla aquí en general, al margen de su relación con Juana, nos permite entender mejor en qué medida Paco acepta con normalidad el cuerpo de su pareja y nos ayuda a poner en contexto el asombro de Paco hacia la pérdida de peso de Juana a través de la dieta, que discutimos más arriba, en el fragmento 56 de la entrevista a Paco. 


\section{El dilema del silencio}

Finalmente, recuperamos un fragmento de la entrevista a Paco que ilustra su posicionamiento como cuidador a lo largo de su relación de pareja. La conversación en esta parte versa sobre las quejas cotidianas de Juana y la atención que merecen en el día a día:

64 Entrevistadora: y tú qué la dices cuando hace esos comentarios quejosos

65 (4)

66 Paco: hombre pues yo (3) intento quitar hierro al asunto. la verdad es que tiene seis o siete kilos. no lo sé exactamente. más que antes. pero para mí no es una cosa determinante o fundamental en mi relación con ella. es una cosa más que secundaria y yo la verdad es que podría poner más énfasis en quitar hierro al asunto pero la verdad es que la digo "no te preocupes. ya lo dijo mi hermana que es una tontería y no merece la pena". pero ella lo vive mal. quizás yo no sé si estoy muy acertado a la hora de quitar hierro al asunto pero ella se la ve que lo vive mal. al menos aparentemente. una cosa es lo que se dice y otra lo que se piensa

67 Entrevistadora: vale. desde que tú la conoces, esto que cuentas tu las has notado aparte del embazado que ella hay intentado ocultar su cuerpo o quizás no mostrarse ante ti de forma más natural

$68(5)$

69 Paco: yo creo que más que con el cuerpo en sí o quizás por algún kilo de más. es por la depilación. vamos eso es para ella. incluso a la hora de ponderar es peor todavía. dice "estoy con estas melenas" ja ja

70 Entrevistadora: ja ja si?

71 Paco: cuando nos conocimos y empezamos a salir ella era como (3) me ha contado incluso que de pequeña estaba con las primas en la misma habitación de vacaciones se cambiaba. se quitaba la ropa y tal de una forma que se quitaba la ropa y se ponía el pijama sin que nadie viera nada. era una. siempre ha tenida ella bastante (3) o ha tenido mucha intimidad con su cuerpo o lo ha vivido de una forma muy (3) no sé. muy particular

72 Entrevistadora: y ahora?

73 Paco: ahora está con la lactancia. el otro día abrí la puerta y estaba ella con el pecho fuera dando de mamar al niño. ahora es distinto. entre nosotros dos sí. ha cambiado mucho es lógico después de llevar viviendo juntos seis años. yo pienso que algo de confianza se debe de tener.

En la línea 66, Paco plantea su dilema de "quitar hierro al asunto" cuando Juana habla de sus preocupaciones por el peso, sabiendo que "ella lo vive mal" (aunque no lo manifiesta explícitamente). Describe un entorno cotidiano donde se percibe pero no se llega a abordar un problema de fondo. La paradoja es que hablar expresamente de algo supone constituirlo como problema y alimentar la preocupación (donde la propia preocupación es problema); sin embargo, el silencio puede 
resultar también problemático, al permitir que los pensamientos y comportamientos problemáticos persistan soterradamente.

A continuación, Paco revisa algunas situaciones vividas con Juana y su relato sugiere que él presta atención a las preocupaciones de Juana con su cuerpo (líneas 69 y 71). En la línea 71, estas descripciones se aderezan sugiriendo un rasgo estable en Juana ("siempre") que la caracteriza ("particular"). Los pudores de Juana parecen superados en la actualidad, lo cual Paco atribuye a la experiencia de convivencia.

\section{Discusión y conclusiones}

En el análisis vislumbramos a una mujer construyendo su identidad en diferentes momentos vitales y tomando decisiones en relación a su cuerpo. Siguiendo a Le Breton ${ }^{5}$, en el concepto de apariencia se establece una relación entre la imagen que las personas ofrecen de su cuerpo a los demás y a uno mismo. Hay un dilema entre lo que quiere ser y lo que quiere representar ante la mirada de los demás, intentando alcanzar una satisfacción sin lograrlo completamente.

La adolescencia es un momento evolutivo en el que el físico es especialmente relevante debido a los fuertes y rápidos cambios que se producen. ${ }^{17,18}$ El cuerpo y la apariencia física se cuestionan, existiendo una preocupación hacia la imagen corporal y el deseo de gustar. ${ }^{36,37}$ Este es el primer momento vital señalado por Juana donde se produce un dilema en el afrontamiento de los cambios producidos. Juana decide tapar sus atributos sexuales, utilizando la ropa como vehículo de control de lo que se quiere mostrar. ${ }^{23,24}$ En el momento vital de la adolescencia, Juana reacciona de una forma opuesta a las directrices de su contexto sociocultural. ${ }^{25}$ Además, el recelo a la intimidad se manifiesta también ante la familia, con la que no encuentra un referente de confianza que le permita elaborar la aceptación de sus formas corporales.

Igualmente, la funcionalidad del cuerpo en la vida de Juana cambia de antes a después del embarazo. El cuerpo pasa de ser vivido como algo que genera malestar a algo útil; en concreto, los pechos dejan de tener una funcionalidad erótico-sexual, para tener un objetivo biológico en el ámbito de la maternidad: Alimentar. Además, los cambios biológicos ocurridos en el embarazo y parto han dado lugar a un incremento de satisfacción en las relaciones íntimas de Juana.

Sin embargo, esta satisfacción por el cambio de funcionalidad se contrapone a la insatisfacción causada por los kilos "de más" después del embarazo y hacia los intentos de modificar el cuerpo antes y después del embarazo. Dichos intentos llevaron a Juana a realizar dos dietas de dudosos beneficios. Distintas corrientes han señalado que la insatisfacción corporal se encuentra asociada a la formación y estructuración de la identidad. ${ }^{19,38}$ En esta línea, la hipótesis del "escape" señala que las personas que presentan insatisfacción respecto a su cuerpo se perciben de forma negativa y desean escapar a través del control de su cuerpo. ${ }^{39}$ 
La primera dieta coincide con el momento de independencia hacia la familia de origen y comienzo de la vida en pareja. Dicho cambio produce modificaciones en los hábitos alimentarios que a su vez ocasionan un incremento de peso. Bastaría quizás con volver a una alimentación similar a la que mantenía con su familia de origen, o haber creado una nueva alimentación asesorándose por un nutricionista-dietista. Sin embargo, la decisión de Juana fue acudir a un centro de adelgazamiento rápido. La segunda dieta es denominada por Juana como "una dieta de limpieza" como preparación al embarazo. Esta decisión es muy habitual en la cultura occidental ya que muchas mujeres se amparan en recomendaciones médicas realizadas a mujeres con sobrepeso en la gestación. Por ejemplo, se recomienda bajar de peso para facilitar la concepción, o para evitar la diabetes gestacional u otros problemas asociados a la obesidad en el embarazo. El problema es que muchas mujeres con normopeso siguen estas recomendaciones propiciando un efecto rebote en el peso durante la gestación. Además, en la entrevista se enfatiza el típico equilibrio buscado por consumidores de dietas: perder peso sin dejar de disfrutar de la comida.40,41

En la actualidad, Juana siente malestar por los kilos que ha ganado durante el embarazo y muestra ambivalencia respecto al método que seguirá para eliminarlos. Siguiendo a Carey, ${ }^{42}$ algunas personas preocupadas por huir del supuesto sobrepeso recurren a dietas rápidas y restrictivas que pueden ocasionar efectos rebote en el organismo. Estas conductas son normalizadas en un contexto social que halaga los esfuerzos por controlar el peso aun cuando se parta de un peso normal. Así, las pérdidas de peso y el poder que infiere la persona se convierten, con frecuencia, en una parte significativa de la identidad.

La pareja de Juana, Paco, busca una explicación al sufrimiento de Juana que curiosamente Juana no ha verbalizado: La presión sociocultural. Acaso Paco reproduce a su manera la crítica de Featherstone ${ }^{43}$ a la cultura consumista. Según dicho autor, ${ }^{43}$ la proliferación de imágenes del cuerpo en la cultura contemporánea "crea un mundo en el que los individuos se hacen vulnerables emocionalmente, monitorizándose constantemente en busca de imperfecciones corporales que ya no se podrían considerar naturales" (p.175).

En otras palabras, la cultura consumista constituye cuerpos, y en particular cuerpos de mujeres, como imágenes, de manera que el aspecto corporal ya no se constituye como algo natural o inevitable sino como una cuestión de responsabilidad individual, que se debe trabajar para presentarse públicamente. La cultura del consumo promueve una subjetividad corporal, tal y como señala Featherstone, ${ }^{43}$ en la que "una experiencia sensual [...]queda completamente sumergida entre los beneficios reclamados por el mercado y por los expertos en salud” (p.185-6).

Por otra parte, esta concepción de la influencia sociocultural como algo independiente de la psicología individual reproduce la idea de que el control alimentario es una manifestación psicopatológica ${ }^{44}$ y las mujeres sus víctimas pasivas frente a los originadores del discurso público. ${ }^{45}$ Paco también se alinea con estudios sociológicos sobre TCA que tienden a identificar como 
"influencia sociocultural" solo la que proviene de los medios y es desaprobada por los discursos sanitarios oficiales, olvidando que la promoción de la delgadez también se realiza desde las instituciones de salud. ${ }^{46-48}$

En relación al deseo masculino, el homenaje de Paco a la mujer hermosa traslada una declaración de principios sobre el valor del cuerpo "natural" y "proporcionado" frente a aberrantes intervenciones artificiales y frente a ciertos otros estándares sociales, que se formulan como independientes de la misma apreciación de la belleza natural proporcionada, y del mismo principio que postula que el hombre reacciona con deseo hacia la mujer. ${ }^{49}$

Estas consideraciones sobre la belleza femenina desde la óptica heterosexual de un varón alcanzan relevancia en relación con el análisis de Malson y Ussher ${ }^{50}$ sobre la idealización de la delgadez. Según estas autoras, la ligazón entre belleza y delgadez se sitúa en una construcción del cuerpo femenino como atractivo en una matriz heterosexual, donde la mujer es objeto de deseo masculino. La cara B de este planteamiento es la construcción del cuerpo gordo como poco atractivo para los hombres y la razón del "fracaso" en sus relaciones con hombres. Malson y Ussher ${ }^{50}$ ubican esta construcción en el seno de un discurso romántico tradicional en el que la mujer hermosa consigue a un hombre con el que alcanza la felicidad.

En este sentido, encontramos que tanto las consideraciones de Paco sobre las influencias que sustentan el problema de su pareja, como sus valoraciones sobre belleza ideal y real, constituyen instancias de consumo de discurso público, elaborado desde las circunstancias particulares de los participantes y con su personal capacidad de articulación descriptiva.

Examinando los posicionamientos de Paco con respecto a la convivencia diaria con las dificultades de Juana, identificamos una situación paradójica para los cuidadores: Si bien "hablar de los problemas" es un recurso para confrontarlos, Paco justifica la evitación de hablar en el temor a que nombrar problemas genere preocupación (donde la misma preocupación alimenta el problema de imagen corporal). Este "dilema del silencio" concuerda con las experiencias identificadas por Perkins et al..$^{51}$ en cuidadores de personas con bulimia, que relataban no haber dado suficiente importancia al problema o haberlo hecho demasiado tarde. En una reciente publicación $\mathrm{n}^{52}$ hemos desarrollado estas paradojas en la atención a personas con TCA por sus cuidadores.

En definitiva, el análisis de biografías de personas sin diagnóstico nos permite entender diferentes formas de posicionarse en el contexto sociocultural de la cultura occidental. A su vez, nos puede facilitar crear acciones donde podamos construir una mirada crítica hacia el contexto contribuyendo a que las mujeres elaboren su identidad y la vivencia hacia su cuerpo de una forma libre. 


\section{Referencias}

1. Bishop R. The pursuit of perfection: a narrative analysis of how women's magazines cover eating disorders. Howard Journal of Communications 2001; 12:221-240.

2. Griffin J, Berry EM. A modern day holy anorexia? Religious language in advertising and anorexia nervosa in the West. European Journal of Clinical Nutrition 2003; 57:43-51.

3. Raich RM. Imagen corporal: conocer y valorar el propio cuerpo. Madrid: Pirámide; 2000.

4. Cash TF, Smolak L. Body image: a handbook of science, practice and prevention. New York: Guilford; 2011.

5. Le Breton D. Antropología del cuerpo y la modernidad. Buenos Aires: Nueva Visión; 2002.

6. Carrillo MAV. Publicidad y anorexia: influencia de la publicidad y otros factores en los trastornos de la conducta alimentaria. Madrid: Ciencias Sociales; 2002.

7. Sierra J. Las chicas de alambre. Madrid: Alfaguara; 1999.

8. Freire E. Cuando comer es un infierno: confesiones de una bulímica. Madrid: Aguilar; 2002.

9. López-Guimera Gl, Sánchez-Carracedo D. Prevención de las alteraciones alimentarias: fundamentos teóricos y recursos prácticos. Madrid: Pirámide; 2010.

10. Gracia Arnaiz M. Somos lo que comemos: estudios de alimentación y cultura en España. Barcelona: Ariel Antropología; 2002.

11. Mernissi F. El harén de occidente. Barcelona: Espasa hoy; 2006.

12. Escobar M, Román H. La presentación del yo en el ciberespacio: un análisis de las autodefiniciones personales en blogs y redes sociales. Revista de Psicología Social 2011; 26(2):207-222.

13. Lenhart A, Purcell K, Smith A, Zickuhr K. Social media and mobile internet use among teens and young adults. Journal Pew Internet and American Life Project [Internet] 3 fev. 2010. Disponivel em: http://www.pewinternet.org/files/old-media/Files/Reports/2010/PIP_Social_Media_and_Young_ Adults_Report_Final_with_toplines.pdf

14. MacSween M. Anorexic bodies: a feminist and sociological perspective on anorexia nervosa. Londres: Routledge; 1993.

15. Jones DC, Crawford JK. The peer appearance culture during adolescence: gender and body mass variations. Journal of Youth and Adolescence 2006; 35:257-269.

16. Paxton SJ, Eisenberg ME, Neumark-Sztainer D. Prospective predictors of body dissatisfaction in adolescent girls and boys: a five- year longitudinal study. Developmental Psychology 2006; 42:888-899.

17. Rogers RF, Paxton SJ, Chabrol H. Effects of parental comments on body dissatisfaction and eating disturbances in young adults: a sociocultural model. Body Image: An International Journal of Research 2009; 6:171-177.

18. Castro AM, Gómez Peña M. Corporalidad en el contexto de la psicoterapia. Psicología desde el Caribe. Universidad del Norte 2011; 27:223-252. 
19. Toro J. El adolescente ante su cuerpo. Cuerpo, vestido y sexo. Madrid: Pirámide; 2013.

20. Urpiñas Vila E. Atención a los adolescentes consumidores de sustancias desde la red infanto juvenil: Centro de salud mental infantojuvenil y hospital de día de adolescentes. Informaciones Psiquiátricas 2014; 215(1):87-96.

21. Toro J, Gómez- Peresmitré G, Sentís J. Eating disorders and body image in Spanish and Mexican female adolescents. Social Psychiatry and Psychiatric Epidemiology 2006; 41:556-565.

22. Eisenberg ME, Neumark-Sztainer D. Associations of weight- based teasing and emotional well-being among adolescents. Archives of Pediatrics and Adolescent Medicine 2003; 157:733-741.

23. Pomerantz S. Style and girl culture. In: Mitchell CA, Reid- Walsh J, directores. Girl culture. v. 1. Westport: Greenwood Press; 2008. p. 64-72.

24. Martínez E, Vázquez AI. Marketing de la moda. Madrid: Pirámide; 2006.

25. Esteban ML. Antropología del cuerpo. Género, itinerarios corporales, identidad y cambio. Barcelona: Bellaterra; 2004.

26. Márquez Guerrero M. El discurso como síntoma, criterio de pronóstico y elemento terapéutico. In: Gallardo Paúls B, Moreno Campos V, editoras. Estudios de lingüística clínica. v. 5: aplicaciones clínicas. Valencia: Universitat de Valéncia; 2010. p. 117-45.

27. Solano Pinto N, Solbes I. Imagen corporal en personas con trastorno alimentario. In: Rede Naus, coordinadores. Estudos socioculturais em alimentação e saúde. v. 5. Série Sabor Metrópole. [en prensa].

28. Díaz Martínez F, Solano Pinto N, Solbes Canales I, Calderón López C. Eating disorders in the course of life: a qualitative approach to vital change. REJP, European Journal of Psychotherapy \& Counselling [Internet] 2015; 17(2).

29. Bowman G. Thin: a memoir of anorexia and recovery. London: Penguin; 2007.

30. Saukko P. The anorexic self: a personal, political analysis of a diagnostic discourse. Albany, NY: State University of New York (SUNY) Press; 2008.

31. Romero A. Peso cero. Colección Avatar. Valencia: Diálogo-Editilde; 2007.

32. Welsh I. La vida sexual de las gemelas siamesas. Barcelona: Anagrama; 2015.

33. Cervera P, Clapés J, Rigolfas R. Alimentación y dietoterapia. Madrid: McGraw- Hill; 2005.

34. Pomerantz A. Extreme case formulations: a way of legitimazing claims. Human Studies 1986; 9:219-229.

35. Potter J. La representación de la realidad: discurso, retórica y construcción social. Barcelona: Paidós Ibérica; 1998.

36. Miranda VPN, Conti MA, Bastos RR, Caputo Ferreira MEC. Insatisfação corporal em adolescentes brasileiros de municípios de pequeno porte de Minas Gerais. J. Bras. Psiquiatr. 2011; 60(3):190-197.

37. Miranda VPN, Soares Amaral AC, Sousa Fortes L, Conti MA, Caputo Ferreira ME. Estudo transversal sobre imagen corporal de adolescentes. Revista Psicologia: Teoria e Prática 2013; 15(3):151-162.

38. Becker Lewkowicz A, Lewkowic S. Escuchando las voces del cuerpo. Revista Uruguaya de Psicoanálisis 2013; 116:35-42. 
39. Kirszman D, Salgueiro MC. El enemigo en el espejo. De la insatisfacción corporal al trastorno alimentario. Madrid: TEA Ediciones; 2002.

40. Coveney J. Food, morals and meaning: the pleasure and anxiety of eating. Londres: Routledge; 2000.

41. Moraes Prata Gaspar MC. Control of eating behaviour and eating pleasure among French female college students. Menu: Journal of Food and Hospitality Research 2012; 12(1):92-96.

42. Carey E. Eating, food and the female body in the media and medicine: a feminist analysis of eating disorders. Socheolas: Limerick Student Journal of Sociology 2009; 1(1):31-45.

43. Featherstone M. The body in consumer culture. Theory, Culture \& Society 1982; 1:18-33.

44. Benveniste J, LeCouteur A,Hepworth J. Lay theories of anorexia nervosa: a discourse analytic study. J. Health Psychology 1999; 4:59-69.

45. Robertson M. Starving in the silences: an exploration of anorexia nervosa. Sydney: Allen \& Unwin; 1992.

46. Yager J. Has our 'healthy’ life-style generated eating disorders? Western J. Medicine 1992; 157:679-80.

47. Iris Bazán C, Ferrari EL. La delgadez, las dietas hipocalóricas y la salud: un estudio transcultural. Quaderns de Psicología 2012; 14(2):37-53.

48. Díaz R. La belleza es salud, la medicalización lingüística de la publicidad de los cosméticos. Revista Contextos 2002; 19-20 (37-40):109-121.

49. Easthope A. What a man's gotta do: the masculine myth in popular culture. Boston: Unwin Hyman; 1990.

50. Malson H, Ussher JM. Body poly-texts: discourses of the anorexic body. Journal of Community and Applied Social Psychology 1996; 6(4):267-80.

51. Perkins S, Winn S, Murray J, Murphy R, Schmidt U. A qualitative study of the experience of caring for a person with bulimia nervosa. Part 1: the emotional impact of caring. International Journal of Eating Disorders 2004; 36(3):256-268.

52. Díaz F, Solano Pinto N. Reconstructing support relations: biographic accounts by carers for people with eating disorders. 6th Qualitative Research in Mental Health; 25-27 Mayo 2016; Chaniá, Grecia. 
